\title{
PENGARUH HAMBATAN SAMPING, $U$-TURN DAN JALINAN TERHADAP VOLUME LALU LINTAS RUAS JALAN MENUJU ARAH NUSA DUA PADA SIMPANG DEWA RUCI
}

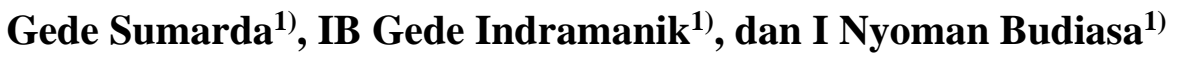 \\ 1) Program Studi Teknik Sipil, Universitas Ngurah Rai, Denpasar, Bali \\ gdsumarda@gmail.com
}

\begin{abstract}
Traffic congestion on the road towards Nusa Dua at the DewaRuci intersection is caused by several main factors, including Side Obstacles, $U$-turn and Braided. In analyzing the performance of roads in this study using the Manual of Indonesian Road Capacity 1997, while to obtain a model of the relationship between traffic volume and the factors that influence it using regression analysis. The regression analysis was carried out using the help of a computer program, namely the Static Package for the Social Sciences version 26. The results showed that the highest traffic volume occurred during the peak hours of the day at $4575.85 \mathrm{pcu} / \mathrm{hour}$, capacity $5076 \mathrm{pcu} / \mathrm{hour}$ so that the value of the degree of saturation is 0.90 and the level of service at level E. The results of the analysis obtained are in the form of multiple linear regression equations, with the model of the relationship between traffic volume and the factors that influence it shown by the equation $Y=886.203+0.190 X_{1}+2.360 X_{2}+0.570 X_{3}$.
\end{abstract}

Keywords: travel speed, road section performance, equation model

\begin{abstract}
ABSTRAK
Kemacetan lalu-lintas ruas jalan menuju arah Nusa Dua pada Simpang Dewa Ruci disebabkan oleh beberapa faktor utama, antara lain: Hambatan Samping, U-turn dan Jalinan. Dalam menganalisis kinerja ruas jalan pada penelitian ini menggunakan panduan Manual Kapasitas Jalan Indonesia 1997, sedangkan untuk memperoleh model hubungan antara volume lalu-lintas dan faktor yang mempengaruhinya menggunakan analisis regresi. Adapun analisis regresi yang dilakukan menggunakan bantuan program komputer yaitu Statisical Package for the Social Sciences versi 26. Hasil penelitian menunjukan bahwa volume lalu-lintas tertinggi terjadi pada jam puncak siang sebesar 4575.85 smp/jam, kapasitas 5076 smp/jam sehingga didapat nilai derajat kejenuhan 0.90 dan tingkat pelayanan pada level E. Hasil analisis yang didapat berbentuk persamaan regresi linear berganda, dengan model hubungan antara volume lalu-lintas dan faktor yang mempengaruhinya diperlihatkan dengan persamaan $Y=886.203+0.190 X_{1}+2.360 X_{2}+0.570 X_{3}$.
\end{abstract}

Kata kunci: kecepatan, kinerja ruas jalan, model regresi 


\section{PENDAHULUAN}

Ruas jalan menuju arah Nusa Dua pada Simpang Dewa Ruci merupakan salah satu ruas jalan di Kabupaten Badung. Pada ruas jalan tersebut banyak terdapat pusat pembelanjaan, kantor dan tempat hiburan karena merupakan daerah yang strategis yaitu pusat perkembangan ekonomi. Daerah tersebut merupakan perbatasan antara wilayah Kota Denpasar dengan Kabupaten Badung.

Sebagai pusat perkembangan ekonomi menyebabkan peningkatan volume kendaraan pada ruas jalan menuju arah Nusa Dua pada Simpang Dewa Ruci. Peningkatan volume kendaraan yang melampaui kapasitas jalan akan menimbulkan terjadinya kemacetan lalulintas. Kemacetan lalu-lintas biasanya terjadi di sepanjang ruas jalan Simpang Dewa Ruci arah Sanur menuju Nusa Dua sampai dengan tempat hiburan Grahadi. Kemacetan tersebut berdampak besar terhadap produktifitas kegiatan di area sekitarnya. Selain itu ada beberapa hal penyebab kemacetan lalu- lintas, antara lain: Hambatan Samping, U-turn dan Jalinan. Hambatan samping yang dominan pengaruhnya adalah kendaraan yang keluar masuk Mall Bali Galeria dan tempat hiburan Grahadi.
Dari latar belakang di atas, maka dapat dirumuskan tujuan dilakukannya penelitian ini adalah untuk mengetahui pengaruh Hambatan Samping, U-Turn dan Jalinan terhadap volume lalu lintas ruas jalan menuju arah nusa dua pada simpang Dewa Ruci serta untuk membuat model hubungan antara volume lalu-lintas dengan hambatan samping, U-turn dan Jalinan pada ruas jalan tersebut.

\section{KAJIAN PUSTAKA}

Kemacetan merupakan akibat dari berkembangnya kebutuhan transportasi sedangkan perkembangan penyedia fasilitas transportasi sangat rendah, sehingga prasarana yang ada tidak dapat berfungsi sebagaimana mestinya dan dapat mengganggu kebutuhan prasarana transportasi penduduk kota (Novalia, 2015).

\subsection{Landasan Teori Manual Kapasitas Jalan Indonesia}

Manual Kapasitas Jalan Indonesia (MKJI) 1997 memuat fasilitas jalan perkotaan, semi perkotaan, luar kota dan jalan bebas hambatan. Tujuan analisa MKJI adalah untuk dapat melaksanakan perancangan (planning), perencanaan (design) dan pengoperasionalan lalu-lintas (trafficoperation) pada simpang bersinyal, simpang tak bersinyal, bagian jalinan dan 
bundaran, ruas jalan seperti: jalan perkotaan, jalan luar kota dan jalan bebas hambatan (Anonim, 1997).

\subsection{Variabel Perhitungan Ruas Jalan Perkotaan}

Adapun beberapa variabel yang perlu dihitung dalam menentukan kinerja suatu ruas jalan perkotaan, anatara lain:

\subsubsection{Volume Lalu-lintas}

Volume lalu-lintas adalah jumlah kendaraan yang melewati suatu titik pengamatan dalam satu satuan waktu (hari, jam, menit) (Sukirman, 1994).

\subsubsection{Kecepatan Arus Bebas}

Kecepatan tempuh adalah laju perjalanan yang biasanya dinyatakan dalam kilometer per jam (km/jam) (Hobbs, 1979). Kecepatan arus bebas (FV) didefinisikan sebagai kecepatan pada tingkat arus nol, yaitu kecepatan yang akan dipilih pengemudi jika mengendarai kendaraan bermotor tanpa dipengaruhi oleh kendaraan bermotor lain di jalan.

$$
\mathrm{FV}=\left(\mathrm{FV}_{\mathrm{O}}+\mathrm{FV}_{\mathrm{W}}\right) \times \mathrm{FFV}_{\mathrm{SF}} \times \mathrm{FFV}_{\mathrm{C}} .
$$

\subsubsection{Kapasitas}

Kapasitas didefinisikan sebagai arus lalu-lintas maksimum yang dapat didukung pada ruas jalan pada keadaan tertentu (geometri, komposisi dan distribusi lalulintas dan faktor lingkungan) (Anonim, 1997). Kapasitas adalah jumlah kendaraan maksimum yang dapat melewati suatu penampang jalan pada jalur jalan selama 1 jam dengan kondisi serta arus lalu-lintas tertentu (Suputra, 2019).

$$
\mathrm{C}=\mathrm{Co} \times \mathrm{FC}_{\mathrm{W}} \times \mathrm{FC}_{\mathrm{SP}} \times \mathrm{FC}_{\mathrm{SF}} \times \mathrm{FC}_{\mathrm{CS}}
$$

\subsubsection{Derajat Kejenuhan}

$$
\text { Derajat Kejenuhan }
$$

didefinisikan sebagai rasio arus lalu-lintas terhadap kapasitas pada bagian jalan tertentu.

$$
\mathrm{DS}=\mathrm{Q} / \mathrm{C}
$$

\subsubsection{Tingkat Pelayanan Jalan}

Tingkat pelayanan jalan merupakan indikator yang dapat mencerminkan tingkat kenyamanan suatu ruas jalan yaitu perbandingan antara volume lalu-lintas terhadap kapasitas jalan (Anonim, 2000). Tingkat pelayanan jalan ditentukan dalam suatu skala interval yang terdiri dari 6 tingkat. Tingkatan ini dinyatakan dengan huruf dari A-F, dimana A merupakan tingkat pelayanan tertinggi dan $\mathrm{F}$ merupakan tingkat pelayanan terendah (Morlok, 1988). Tingkat pelayanan jalan tersebut dijelaskan dalam Transportation Research Board. (TRB) 2000 yang dinilai berdasarkan derajat kejenuhannya.

\subsection{Teori $U$-turn}

Pedoman perencanaan putaran balik (U-turn) 2005 bertujuan untuk mendapatkan keseragaman dalam merencanakan putaran balik, baik untuk 
jalan perkotaan maupun jalan luar kota. Hal tersebut dimaksudkan agar dihasilkan perencanaan jalan yang memberikan keselamatan, kelancaran dan kenyamanan bagi pengguna jalan. Dalam pedoman perencanaan putaran balik (u-turn) tahun 2005 berisi tentang bukaan median untuk putaran balik serta ketentuan teknis yang terdiri dari kendaraan rencana, radius putaran, kebutuhan lebar median berdasarkan radius putaran kendaraan rencana, putaran balik pada median sempit, bukaan median, putaran balik di persimpangan bersinyal, lansekap, penempatan rambu lalu-lintas, bagan alir perencanaan putaraan balik dan dampak putaran balik pada median yang tidak memenuhi persyaratan. Definisi Putaran Balik (U-turn) adalah suatu gerak lalulintas kendaraan untuk berputar kembali atau berbelok $180^{\circ}$ (Anonim, 2005).

\subsection{Teori Jalinan}

Berdasarkan MKJI 1997 pengertian jalinan adalah persimpangan dua atau lebih arus lalu-lintas yang bergerak pada satu arah suatu ruas jalan. Dimana arus lalulintas tersebut akan terjadi gerakan menyatu (merging), gerakan memotong (crossing) dan gerakan menyebar (diverging).

\subsection{Analisa Statistik}

Analisis statistik dapat diartikan sebagai upaya mengolah data menjadi informasi, sehingga karakteristik atau sifatsifat data tersebut dapat dengan mudah dipahami dan bermanfaat untuk menjawab masalah-masalah yang berkaitan dengan kegiatan penelitian. Salah satu cabang dari teori statistika adalah analisa regresi (Utama, 2008).

Pengertian regresi adalah suatu alat statistika yang tujuannya membantu memperkirakan atau menaksir nilai variabel yang tidak diketahui dari satu atau beberapa variabel yang diketahui (Utama, 2008). Variabel dalam analisis regresi dibedakan atas 2 jenis yaitu variabel bebas dan variabel tidak bebas (Utama, 2008). Berdasarkan pola hubungannya, analisis regresi terbagi menjadi analisis regresi linier dan analisis regresi non linier. Regresi linier adalah bentuk hubungan dimana variabel bebas $\mathrm{X}$ maupun variabel tergantung $\mathrm{Y}$ sebagai faktor yang berpangkat satu. Salah satu analisis regresi yang sering digunakan dalam persamaan matematis adalah analisis regresi linier berganda (Utama, 2008).

Persamaan regresi berganda merupakan persamaan matematis yang menyatakan hubungan antara sebuah variabel tak bebas (Y) dengan beberapa 
variabel bebas $(\mathrm{X})$. Bentuk pertama dari persamaan regresi berganda adalah (Hakim, 2000):

$\mathrm{Y}=\mathrm{A}_{1}+\mathrm{B}_{1} \cdot \mathrm{X}_{1}+\mathrm{B}_{2} \cdot \mathrm{X}_{2}+\ldots+\mathrm{B}_{\mathrm{n}} \mathrm{X}_{\mathrm{n}}$.

dimana:

Y : variabel tak bebas

$\mathrm{X}_{1}, \mathrm{X}_{2}, \ldots \mathrm{X}_{\mathrm{n}} \quad$ : variabel bebas

A : koefisien intersep

$\mathrm{B}_{1}, \mathrm{~B}_{2}, \ldots \mathrm{B}_{\mathrm{n}} \quad$ : koefisien regresi

Metode regresi digunakan untuk menentukan model persamaan matematis yang terbaik dengan mengacu pada kriteria statistik. Untuk dapat memperoleh hasil regresi terbaik maka harus memenuhi kriteria statistik sebagai berikut uji koefisien determinasi $\left(\mathrm{R}^{2}\right)$, uji ketepatan model (Uji F) dan Uji t. Nilai koefisien determinasi yang terbaik mempunyai nilai antara $0 \mathrm{~s} / \mathrm{d} 1$ atau $\left(0<\mathrm{R}^{2}<1\right)$. Semakin besar nilai $\mathrm{R}^{2}$ (mendekati satu) semakin baik hasil regresi dan semakin mendekati 0 , maka variabel independen secara keseluruhan tidak bisa menjelaskan variabel dependen. Uji $\mathrm{F}$ bertujuan untuk mengetahui ada atau tidaknya pengaruh simultan (bersamasama) yang diberikan variabel bebas (X) terhadap variabel terikat (Y). Dan uji t bertujuan untuk mengetahui ada atau tidaknya pengaruh parsial (sendiri) yang diberikan variabel bebas (X) terhadap variabel terikat (Y) (Hakim, 2000).

\section{METODE PENELITIAN}

Secara keseluruhan kegiatan penelitian ini dapat digambarkan kedalam bagan alir sebagai berikut:

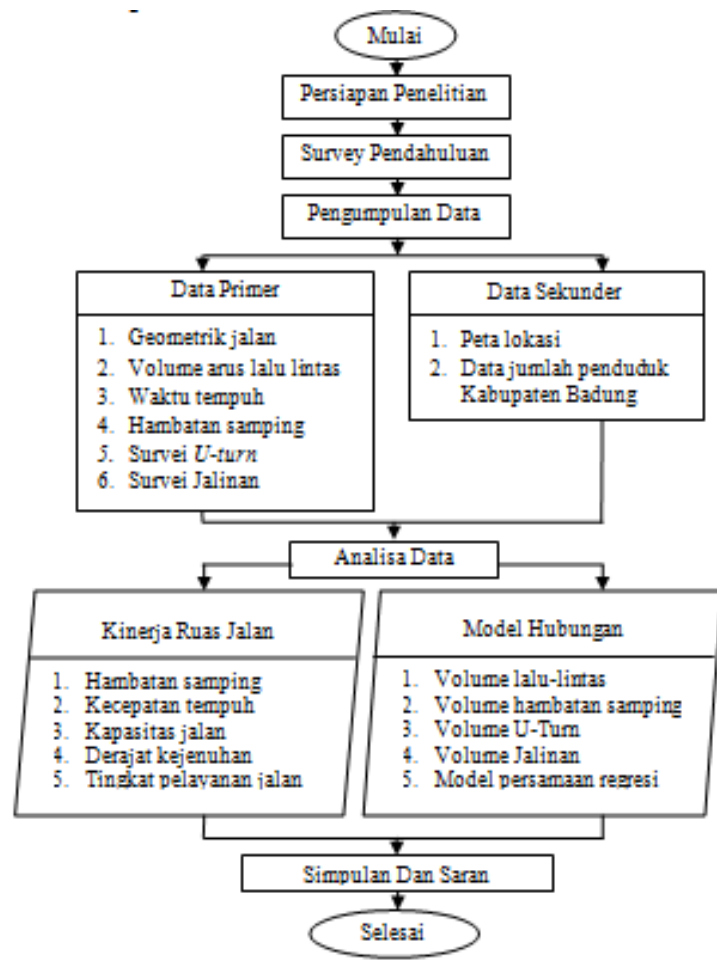

Gambar 1. Diagram Alir Penelitian

Kegiatan penelitian diawali dengan survey pendahuluan yaitu survey awal untuk menentukan atau memilih lokasi studi yang dianggap layak sebagai obyek penelitian. Dalam survei pendahuluan ditemukan lokasi kemacetan lalu-lintas di ruas jalan menuju arah Nusa Dua pada Simpang Dewa Ruci yang terletak di Kecamatan Kuta Kabupaten Badung. Sebagai gambaran kondisi ruas jalan pada obyek penelitian dapat dilihat pada Gambar 2 sebagai berikut: 


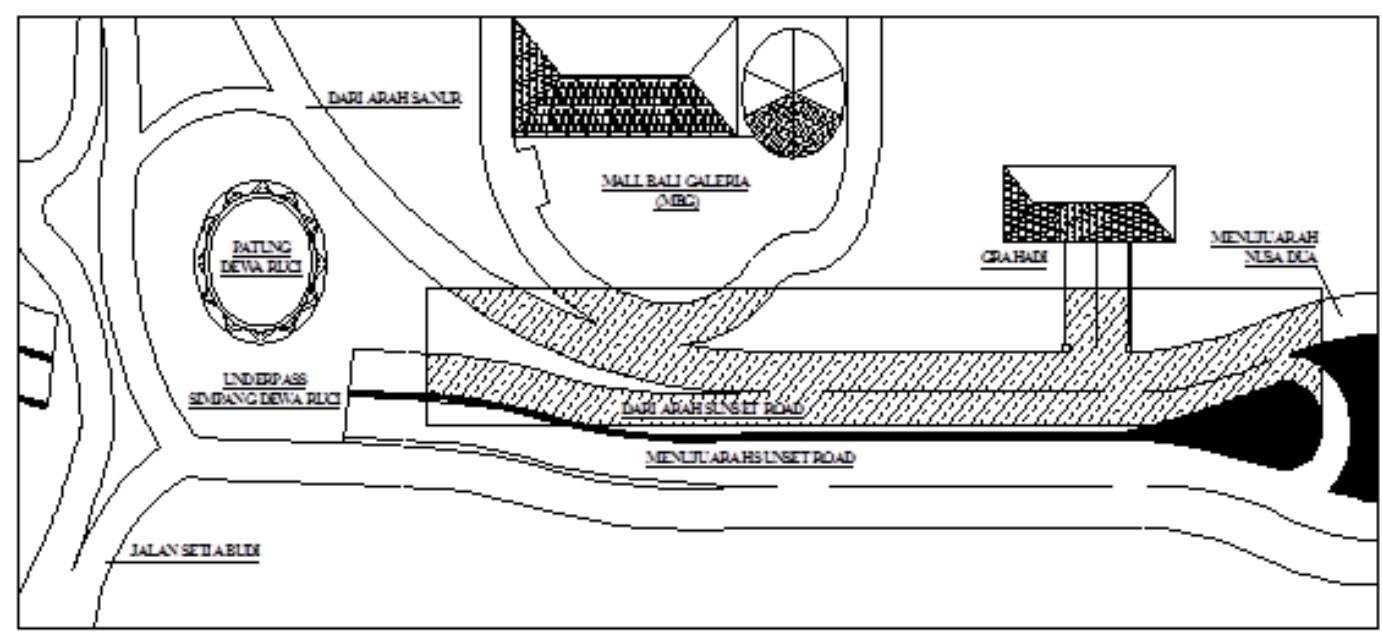

Gambar 2. Layout Obyek Penelitian

Berdasarkan hasil pengamatan di lokasi penelitian, ada beberapa faktor yang menyebabkan terjadinya kemacetan yaitu antara lain adanya kendaraan keluar masuk Mall Bali Galeria dan Grahadi, adanya fasilitas putaran balik atau $u$-turn, serta adanya jalinan. Dari data awal yang diperoleh maka dapat dijadikan bahan untuk menentukan topik penelitian, mempersiapkan literatur pendukung serta mempersiapkan alat dan bahan saat melakukan survei lapangan.

Pengumpulan data yang dilakukan dalam penelitian ini ada 2 yaitu data primer adalah data yang didapat secara langsung melalui survei lapangan dan data sekunder adalah data yang diambil dari data yang telah ada dan telah disurvei sebelumnya oleh pihak atau lembaga lain. Data primer yang dibutuhkan dalam penelitian ini antara lain: geometrik jalan, volume lalu-lintas, data hambatan samping, data $u$-turn dan data jalinan. Survei lapangan dilaksanakan selama 16 jam dengan alat bantu kamera CCTV. sedangkan data sekunder yang diperlukan adalah berupa data jumlah penduduk yang diambil dari Badan Pusat Statistik (BPS) Kabupaten Badung yaitu Kabupaten Badung Dalam Angka Tahun 2019 (Anonim, 2019).

Setelah melakukan pengumpulan data dilanjutkan dengan Analisa Data sesuai dengan tujuan penelitian dan membuat kesimpulan sesuai hasil analisa.

\section{HASIL DAN PEMBAHASAN}

\subsection{Data Volume Lalu-lintas}

Dari hasil analisis volume lalu-lintas didapatkan 3 jam puncak yaitu jam puncak pagi, jam puncak siang dan jam puncak sore. Hasil analisis data volume ditampilkan pada Tabel 1. Dari tabel tersebut diketahui volume tertinggi terjadi pada jam puncak siang. 
Tabel 1. Volume Lalu-lintas pada Jam Puncak Pagi, Siang dan Sore

\begin{tabular}{cccc}
\hline \multirow{2}{*}{ Waktu } & \multirow{2}{*}{ Jam } & \multicolumn{2}{c}{ Total Volume } \\
\cline { 3 - 4 } & & kend/jam & smp/jam \\
\hline Jam Puncak Pagi & $09.00-10.00$ & 6526 & 3793.70 \\
Jam Puncak Siang & $14.15-15.15$ & 7254 & 4575.85 \\
Jam Puncak Sore & $16.00-17.00$ & 7051 & 4401.30 \\
\hline
\end{tabular}

\subsection{Kelas Hambatan Samping}

Frekwensi hambatan samping berbobot pada jam puncak pagi, jam puncak siang, jam puncak sore hasil perhitungan, beserta kelas hambatan sampingnya dapat dilihat pada Tabel 2 berikut ini:

Tabel 2. Kelas Hambatan Samping dan FCSF pada Jam Puncak

\begin{tabular}{ccccccc}
\hline No & $\begin{array}{c}\text { Jam } \\
\text { Puncak }\end{array}$ & Waktu & $\begin{array}{c}\text { Frekwensi } \\
\text { Berbobot }\end{array}$ & Kode & $\begin{array}{c}\text { Kelas Hambatan } \\
\text { Samping }\end{array}$ & $\begin{array}{c}\text { Nilai } \\
\text { FCsf }\end{array}$ \\
\hline 1 & Pagi & $09.00-10.00$ & 196.30 & L & Rendah & 0.97 \\
2 & Siang & $14.15-15.15$ & 565.10 & H & Tinggi & 0.90 \\
3 & Sore & $16.00-17.00$ & 609.00 & H & Tinggi & 0.90 \\
\hline
\end{tabular}

\subsection{Analisis Kecepatan Arus Bebas dan} Kecepatan Tempuh

Dari hasil perhitungan kecepatan arus bebas diperoleh dengan membandingkan anatara kecepatan arus bebas dengan kecepatan tempuh pada ruas jalan menuju arah Nusa Dua di Simpang Dewa Ruci. Ada pun hasil perhitungan tersebut akan diperlihatkan pada Tabel 3 dibawah ini:

Tabel 3. Perhitungan Kecepatan Arus Bebas

\begin{tabular}{cccc}
\hline \multirow{2}{*}{ Jam Puncak } & \multicolumn{3}{c}{ Kecepatan Arus Bebas(km/jam) } \\
\cline { 2 - 4 } & Sepeda Motor & Kendaraan Ringan & Kendaraan Berat \\
\hline Pagi & 40.44 & 49.85 & 43.26 \\
Siang & 36.77 & 45.32 & 39.33 \\
Sore & 36.77 & 45.32 & 39.33 \\
\hline
\end{tabular}

\subsection{Kapasitas Jalan}

Hasil perhitungan kapasitas jalan pada ruas jalan menuju arah Nusa Dua di
Simpang Dewa Ruci menggunakan Persamaan 2 dapat dilihat pada Tabel 4 dibawah ini: 
Tabel 4. Perhitungan Kapasitas Jalan pada Jam Puncak

\begin{tabular}{ccccccccc}
\hline No & $\begin{array}{c}\text { Jam } \\
\text { Puncak }\end{array}$ & $\mathrm{C}_{\mathrm{O}}$ & $\mathrm{FC}_{\mathrm{W}}$ & $\mathrm{FC}_{\mathrm{SP}}$ & $\mathrm{FC}_{\mathrm{SF}}$ & $\mathrm{FC}_{\mathrm{CS}}$ & $\begin{array}{c}\text { Kapasitas (C) per } \\
\text { lajur }\end{array}$ & $\begin{array}{c}\text { Kapasitas Total } \\
(\mathrm{C})\end{array}$ \\
\hline 1 & Pagi & 1500 & 1.00 & 1.00 & 0.97 & 0.94 & 1367.70 & 5470.80 \\
2 & Siang & 1500 & 1.00 & 1.00 & 0.90 & 0.94 & 1269.00 & 5076.00 \\
3 & Sore & 1500 & 1.00 & 1.00 & 0.90 & 0.94 & 1269.00 & 5076.00 \\
\hline
\end{tabular}

\subsection{Derajat Kejenuhan dan Tingkat} Pelayanan

Hasil analisis perhitungan derajat kejenuhan dan tingkat pelayanan pada jam puncak pagi, siang dan sore di ruas jalan menuju arah Nusa Dua di Simpang Dewa Ruci dapat dilihat pada Tabel 5 di bawah ini:

Tabel 5. Perhitungan Derajat Kejenuhan pada Jam Puncak

\begin{tabular}{cccccc}
\hline Jam puncak & Waktu & $\begin{array}{c}\text { Volume lalu } \\
\text { lintas Max } \\
(\text { smp/jam })\end{array}$ & $\begin{array}{c}\text { Kapasitas (C) } \\
(\text { smp/jam) }\end{array}$ & $\begin{array}{c}\text { Derajat } \\
\text { Kejenuhan } \\
(\mathrm{DS})\end{array}$ & $\begin{array}{c}\text { Tingkat } \\
\text { Pelayanan } \\
\text { Jalan }\end{array}$ \\
\hline Pagi & $09.00-10.00$ & 3793.70 & 5470.80 & 0.69 & Tipe C \\
Siang & $14.15-15.15$ & 4575.85 & 5076.00 & 0.90 & Tipe E \\
Sore & $16.00-17.00$ & 4401.30 & 5076.00 & 0.87 & Tipe E \\
\hline
\end{tabular}

\subsection{Analisis Regresi}

Dalam penelitian ini akan dianalisis adalah hubungan antara volume lalu-lintas dengan faktor yang mempengaruhinya yaitu antara lain faktor hambatan samping, faktor $u$-turn dan faktor jalinan. Dimana volume lalu-lintas merupakan variabel tidak bebas atau variabel dependen sedangkan faktor yang mempengaruhinya merupakan variabel bebas atau variabel independen. Ada pun analisis regresi yang dilakukan menggunakan program komputer SPSS (Statistical Package for the Social
Sciences). Pengujian hipotesis yang dilakukan adalah uji koefisien determinasi (R), uji ketepatan model (F) dan uji t yang dapat diuraikan berikut ini.

\subsubsection{Uji koefisien determinasi $(R)$}

Uji kofisien determinasi dilakukan untuk mengetahui seberapa besar variabel independen yakni hambatan samping, $u$ turn dan jalinan mampu menjelaskan dan mempengaruhi variabel dependen yakni volume lalu-lintas. Hasil uji koefisien determinasi dapat dlihat pada Tabel 6 berikut: 
Tabel 6. Uji Koefisien Determinasi

\begin{tabular}{ccccc}
\hline \multicolumn{5}{c}{ Model Summary } \\
\hline Model & $\mathrm{R}$ & R Square & Adjusted R Square & Std. Error of the Estimate \\
\hline 1 & $.943^{\mathrm{a}}$ & .889 & .883 & 205.11440 \\
\hline \multicolumn{4}{l}{ a. Predictors: (Constant), Jalinan, U-Turn, Hambatan Samping } \\
\hline
\end{tabular}

Berdasarkan Tabel 6 diatas dapat disimpulkan bahwa nilai variabel independen mempengaruhi variabel dependen sebesar 0.889 atau $88.9 \%$ dan sisanya yakni $11.1 \%$ dipengaruhi oleh faktor lain yang tidak diteliti oleh penulis.

\subsubsection{Uji ketepatan model (Uji F)}

Uji $F$ bertujuan untuk menguji apakah semua variabel independen berpengaruh secara simultan terhadap variabel dependen. Hasil analisa SPSS untukuji ketepatan model (uji F) dapat dilihat pada Tabel 7.

Tabel 7. Uji Ketepatan Model (Uji F)

\begin{tabular}{ccccccc}
\hline \multicolumn{7}{c}{ ANOVA $^{\mathrm{a}}$} \\
\hline & Model & Sum of Squares & df & Mean Square & F & Sig. \\
\hline \multirow{3}{*}{1} & Regression & 19196145.923 & 3 & 6398715.308 & 152.090 & $.000^{\mathrm{b}}$ \\
& Residual & 2398099.388 & 57 & 42071.919 & & \\
& Total & 21594245.311 & 60 & & & \\
\hline
\end{tabular}

a. Dependent Variable: Kinerja jalan

b. Predictors: (Constant), Jalinan, U-Turn, Hambatan Samping

Berdasarkan hasil olah data pada Tabel 7diketahui nilai signifikansi uji $\mathrm{F}$ adalah 0.000 yakni lebih kecil daripada 0.05 atau $0.000<0.05$ dan $F_{\text {hitung }}>F_{\text {tabel }}$ yakni 152.090 lebih besar daripada 2.77, maka dapat diinterpretasikan bahwa terdapat pengaruh yang signifikan antara hambatan samping, u-turn dan jalinan secara bersama-sama (simultan) terhadap volume lalu-lintas.

\subsubsection{Uji t}

Uji $\mathrm{t}$ dilakukan untuk mengukur apakah setiap variabel independen berpengaruh terhadap variabel dependen secara parsial. Hasil dari uji t setelah dilakukan olah data dengan menggunakan software SPSS versi 26 dapat dilihat pada Tabel 8 sebagai berikut: 
Tabel 8. Uji t Pengaruh $X$ terhadap $Y$

\begin{tabular}{|c|c|c|c|c|c|c|}
\hline \multicolumn{7}{|c|}{ Coefficients $^{\mathrm{a}}$} \\
\hline & \multirow[t]{2}{*}{ Model } & \multicolumn{2}{|c|}{$\begin{array}{l}\text { Unstandardized } \\
\text { Coefficients }\end{array}$} & \multirow{2}{*}{$\begin{array}{c}\begin{array}{c}\text { Standardized } \\
\text { Coefficients }\end{array} \\
\text { Beta }\end{array}$} & \multirow[t]{2}{*}{$\mathrm{t}$} & \multirow[t]{2}{*}{ Sig. } \\
\hline & & B & Std. Error & & & \\
\hline \multirow{4}{*}{1} & (Constant) & 886.203 & 269.595 & & 3.287 & .002 \\
\hline & $\begin{array}{l}\text { Hambatan } \\
\text { Samping }\end{array}$ & .190 & .185 & .028 & 4.488 & .027 \\
\hline & U-Turn & 2.360 & .173 & .718 & 13.628 & .000 \\
\hline & Jalinan & .570 & .056 & .532 & 10.214 & .000 \\
\hline
\end{tabular}

a. Dependent Variable: Kinerja jalan

Berdasarkan Tabel 8 di atas dapat dilihat bahwa nilai signifikansi hambatan samping sebesar $0.027<0.05$ dan thitung $4.488>t_{\text {tabel }}$ 2.002. Nilai signifikansi $u$-turn sebesar $0.000<0.05$ dan thitung $13.628>t_{\text {tabel }}$ 2.002. Nilai signifikansi jalinan sebesar $0.000<0.05$ dan thitung $10.214>$ tabel 2.002 . Hal ini menunjukan bahwa hipotesis diterima, dimana pengaruh hambatan samping, u-turn, dan jalinan mempengaruhi volume lalu-lintas secara parsial.

\subsection{Persamaan Regresi Berganda}

BerdasarkanTabel 8 diketahui model hubungan antara volume lalu-lintas dengan hambatan samping, u-turn dan jalinan dalam bentuk persamaan regresi berganda sebagai berikut:

$\mathrm{Y}=886.203+0.190 \mathrm{X}_{1}+2.360 \mathrm{X}_{2}+0.570 \mathrm{X}_{3}$

Penjelasan dari persamaan di atas adalah koefisien regresi pada variable hambatan samping $\left(\mathrm{X}_{1}\right)$ sebesar 0.190 bahwa hasil ini dapat diinterpretasikan jika variable hambatan samping $\left(\mathrm{X}_{1}\right)$ mengalami kenaikan sebesar 1 satuan, maka nilai kinerja jalan (Y) akan mengalami peningkatan sebesar $19 \%$ atau 0.19 kali lipat dengan mengasumsikan variable bebas lainnya bernilai tetap. Koefisien regresi pada variabel $u$-turn $\left(\mathrm{X}_{2}\right)$ sebesar 2.360 bahwa hasil ini dapat diinterpretasikan jika variabel u-turn $\left(\mathrm{X}_{2}\right)$ mengalami kenaikan sebesar 1 satuan, maka nilai kinerja jalan (Y) akan mengalami peningkatan sebesar $236 \%$ atau 2.36 kali lipat dengan mengasumsikan variabel bebas lainnya bernilai tetap.Koefisien regresi pada variabel jalinan $\left(\mathrm{X}_{3}\right)$ sebesar 0.570 bahwa hasil ini dapat diinterpretasikan jika variabel jalinan $\left(\mathrm{X}_{3}\right)$ mengalami kenaikan sebesar 1 satuan, maka nilai kinerja jalan (Y) akan mengalami peningkatan sebesar $57 \%$ atau 0.570 kali lipat dengan mengasumsikan variabel bebas lainnya bernilai tetap. 


\section{SIMPULAN DAN SARAN}

\subsection{Simpulan}

Berdasarkan hasil penelitian dan analisis yang dilakukan, maka diperoleh beberapa kesimpulan sebagai berikut:

1. Analisa kinerja yang dilakukan pada daerah studi dapat disimpulkan bahwa jam puncak tertinggi terjadi pada jam puncak siang yaitu pukul 14.15-15.15 wita dengan volume lalu-lintas sebesar 4575.85 smp/jam, volume hambatan samping berbobot yang terjadi 565.10 kejadian/jam yang artinya kelas hambatan samping tergolong tinggi (kode $\mathrm{H}$ ), kecepatan arus bebas pada sepeda motor adalah $36.77 \mathrm{~km} / \mathrm{jam}$, kendaraan ringan adalah $45.32 \mathrm{~km} / \mathrm{jam}$, dan kendaraan berat adalah 39.33 km/jam, kapasitas jalannya sebesar $\quad 5076.00 \quad$ smp/jam sehingga di dapat derajat kejenuhan (DS) sebesar 0.90 sehingga menghasilkan tingkat pelayanan tipe $\mathrm{E}$.

2. Untuk mengetahui pengaruh antara variabel independen yaitu hambatan samping, u-turn dan jalinan terhadap variabel dependen yaitu: volume lalu- lintas, telah dilakukan pengujian hipotesis antara lain uji koefisien determinasi, uji $\mathrm{F}$ dan uji t.

3. Uji koefisien determinasi (R) yaitu didapat nilai 0.889 . Hal ini berarti variabel independen mempengaruhi variabel dependen sebesar $88.9 \%$ tergolong tinggi, sedangkan $11.1 \%$ dipengaruhi oleh faktor lain.

4. Uji F yaitu didapat nilai signifikansi adalah 0.000 yaitu lebih kecil daripada 0.05 dan nilai $F_{\text {hitung }}$ yang didapat 152.090 lebih besar dari nilai $\mathrm{F}_{\text {tabel }}$ yaitu 2.77, sehingga dapat diinterprestasikan bahwa terdapat pengaruh yang signifikan antara variabel independen secara bersama-sama atau simultan terhadap variable dependen.

5. Uji t dilakukan untuk mengukur apakah setiap variabel independen berpengaruh terhadap variabel dependen secara parsial. Diketahui nilai tabel sebesar 2.002 .

6. Untuk hambatan samping nilai signifikansi yang didapat $0.027<$ 0.05 dan thitung sebesar $4.488>$ 
tabel yaitu 2.002, ini berarti terdapat pengaruh yang signifikan antara hambatan samping terhadap volume lalulintas.

7. Untuk u-turn nilai signifikansi yang didapat $0.000<0.05$ dan thitung sebesar $13.628>$ ttabel yaitu 2.002, ini berarti terdapat pengaruh yang signifikan antara u-turn terhadap volume lalulintas.

8. Untuk jalinan nilai signifikansi yang didapat $0.000<0.05$ dan thitung sebesar $10.214>$ t tabel yaitu 2.002, ini berarti terdapat pengaruh yang signifikan antara jalinan terhadap volume lalulintas.

9. Model hubungan antara variable independen yaitu hambatan samping, u-turn dan jalinan dengan variable dependen yaitu volume lalu-lintas berbentuk persamaan regresi linear berganda, dimana persamaan yang di dapat yaitu $\mathrm{Y}=886.203+0.190 \mathrm{X}_{1}+2.360 \mathrm{X}_{2}+$ $0.570 X_{3}$.

\subsection{Saran}

Adapun saran yang penulis berikan untuk mengatasi permasalahan yang terjadi antara lain menambah lebar efektif ruas jalan, memindahkan posisi u-turn untuk menambah panjang jalinan, serta membangun underpass dari arah Sanur menuju jalan Sunset Road dan jalan Setia Budi. Namun saran tersebut memerlukan penelitian lebih lanjut dalam merencanakannya, untuk menghitung dampak dan anggaran biaya yang dikeluarkan dalam perencanaan.

\section{DAFTAR PUSTAKA}

Anonim. (1997). Manual Kapasitas Jalan Indonesia (MKJI). Jakarta.

Anonim. (2000). Highway Capacity Manual. Washington DC: Transportation Research Board.

Anonim. (2005). Pedoman Perencanaan Putaran Balik (U-Turn). Jakarta: Direktorat Jenderal Bina Marga.

Anonim. (2019). Kabupaten Badung Dalam Angka 2019. Badung: Badan Pusat Statistik Kabupaten Badung.

Hakim, A. (2000). Statistik Induktif untuk Ekonomi dan Bisnis. Yogyakarta: Ekonesia.

Hobbs, F. D. (1979). Perencanaan Dan Teknik Lalu Lintas. Yogyakarta: Gadjah Mada University Press.

Morlok, E. K. (1988). Pengantar Teknik Dan Perencanaan Transportasi. Jakarta: Erlangga.

Novalia, C. (2015). Analisa Dan Solusi Kemacetan Lalu Lintas di Ruas Jalan Kota (Studi Kasus Jalan Imam Bonjol - Jalan Sisingamangaraja. Retrieved from digilib.unila website: http://digilib.unila.ac.id/22039/3/SK 
RIPSI TANPA BAB

PEMBAHASAN.pdf

Sukirman, S. (1994). Dasar-Dasar Perencanaan Geometrik Jalan. Bandung: Nova.

Suputra, I. K. (2019). Analisa Kinerja $U$ Turn Dan Ruas Jalan Di Jalan By Pass Ngurah Rai Denpasar (Studi Kasus: Jalan By Pass Ngurah Rai Denpasar Di Depan SPBU Suwung Sanur).

Utama, M. S. (2008). Buku Ajar Aplikasi Analisis Kuantitatif. Denpasar: Sastra Utama. 